\title{
The effect of body mass index on osteoporosis and fracture risk in patients with type 2 diabetes mellitus
}

\author{
(DErol Öten ${ }^{1}$, @Mustafa Çapraz ${ }^{2}$ \\ ${ }^{1}$ Amasya University, Faculty of Medicine, Department of Physical Medicine and Rehabilitation, Amasya, Turkey \\ ${ }^{2}$ Amasya University, Faculty of Medicine, Department of Internal Medicine, Amasya, Turkey
}

Cite this article as: Öten E, Çapraz M. The effect of body mass index on osteoporosis and fracture risk in patients with type 2 diabetes mellitus. J Health Sci Med 2021; 4(6): 882-885.

\begin{abstract}
Aim: Type 2 diabetes mellitus (DM), osteoporosis and obesity are increasingly common diseases due to the increase in the elderly population and the change in eating habits. However, the relationship between diabetes, obesity and osteoporosis has not been fully clarified in studies in the literature. In our study, it was investigated whether the combination of diabetes and obesity caused osteoporosis and increased fracture risk.

Material and Method: Our study was carried out with a total of 95 patients between the ages of 40 and 80 , including 24 males and 71 females, who were tested due to the preliminary diagnosis of osteoporosis and diagnosed with type $2 \mathrm{DM}$ in the physical medicine and rehabilitation outpatient clinic. The demographic characteristics, body mass index (BMI), bone mineral density (BMD) measurements, X-ray imaging, and fracture risk assessment scale (FRAX) calculations of patients were performed. Groups were compared in terms of BMD and FRAX according to the BMI classification.

Results: BMD and FRAX hip values were higher in the obese group according to the BMI classification compared to the preobese/normal group $(\mathrm{p}<0.05)$. In the obese group, the number of patients with a history of low-energy fractures and with identified fractures on X-ray scanning was higher compared to the pre-obese/normal group; however, there was no significant relationship between the groups ( $\mathrm{p}>0.05)$.
\end{abstract}

Conclusion: As a result of our study, it was observed that type 2 DM and obesity were associated with increased fracture risk despite high BMD values.

Keywords: Bone mineral density, osteoporosis, obesity, type 2 diabetes mellitus

\section{INTRODUCTION}

Type 2 diabetes mellitus (DM) is an increasingly widespread metabolic disease that is significantly associated with morbidity and mortality (1). Type $2 \mathrm{DM}$ is characterized by hyperglycemia caused by defects in insulin secretion, efficacy, or both (2). As a result of chronic hyperglycemia and insufficient glycemic control, diabetic complications, including macrovascular (acute coronary syndrome, stroke, claudication intermittence) and microvascular (retinopathy, neuropathy, nephropathy) diseases occur (3).

In addition to macro or microvascular long-term complications, patients with type $2 \mathrm{DM}$ may develop various skeletal system disorders, including osteoporosis and fractures (4). Osteoporosis is the most important metabolic bone disease that develops in type $2 \mathrm{DM}$ patients $(4,5)$. Patients with type $2 \mathrm{DM}$ show an increased risk of fractures due to impaired bone quality (6). Obesity is the most important risk factor for type $2 \mathrm{DM}$ (7). Obesity, which is common in type $2 \mathrm{DM}$, has been found to be associated with high bone mineral density (BMD) (8). However, in some studies, BMD was observed to be low (9) or normal in patients with type $2 \mathrm{DM}$ despite high body weight $(10,11)$.

Therefore, there is no clear conclusion about the relationship between type $2 \mathrm{DM}$ patients and $\mathrm{BMI}$ and BMD in the literature. In this study, it is aimed to investigate whether BMI has a positive or negative effect on vertebral-hip bone mineral density and fragility of bone in patients with type $2 \mathrm{DM}$ and to draw attention to the mutual potential interactions of these common diseases. 


\section{MATERIAL AND METHOD}

Using the hospital automation system, patient data to be used in our study were obtained within the scope of patient information security. In this retrospective study, a total of 95 patients between the ages of 40 and 80 who were diagnosed with type $2 \mathrm{DM}$ and whose BMD values were measured, who applied to the Physical Medicine and Rehabilitation outpatient clinic of Amasya University Hospital between October 2019 and February 2020, were included. The demographic characteristics of the patients are shown in Table 1. Patients who have previously received or were receiving osteoporosis treatment were not included in our study. Ethics committee approval for the study was received from the Amasya University Non-interventional Clinical Researchs Ethics Committee (Date: 03.09.2020, Decision No: 9/104). All procedures were carried out in accordance with the ethical rules and the principles of the Declaration of Helsinki.

\begin{tabular}{|lcc|}
\hline \multicolumn{3}{|c|}{ Table 1. Demographic features type 2 DM patients } \\
\hline \multicolumn{3}{|c|}{ To5 } \\
\hline Age & 60.589 & \pm 8.20 \\
Gender & & \\
$\quad$ Male & 24 & $25.3 \%$ \\
Famale & 71 & $74.7 \%$ \\
BMI & & \\
BMI $<30$ (Pre-obese/Normal) & 26 & $27.4 \%$ \\
BMI $\geq 30$ (Obese) & 69 & $72.6 \%$ \\
\hline
\end{tabular}

Blood tests (Hemogram, biochemistry, electrolyte levels, vitamin levels) and thoracolumbar spine X-rays are routinely requested from patients who apply to our outpatient clinic for osteoporosis screening. Weight and height are measured and BMI is calculated with the TANITA MC-180MATM (Tanita Corporation, Japan) device. L1-L4 posteroanterior lumbar spine, femur total and femoral neck BMD measurements are then performed on the dual-energy Hologic DXA device. BMD values are calculated by $\mathrm{T}$ scores defined according to peak young adult bone density values. According to the World Health Organization (WHO) classification, patients with a $\mathrm{T}$ score $\leq-2.5$ are considered osteoporotic, those with a score between -2.5 and -1 are considered osteopenic, and those with a score of $\geq-1$ are considered normal (12). Fracture risk assessment scale (FRAX) is a fracture assessment tool developed by WHO. FRAX is a scale that can calculate the ten-year fracture risk in terms of hip or major fractures (hip, wrist, humerus or spine fractures) (12). In this scale age, BMI, low-energy fracture history, family history of hip fractures, current smoking, alcohol use (alcohol 3 or more units/day), and other secondary osteoporosis causes are used to calculate. Also, femoral neck T scores are included in the calculation (13) Figure 1 shows the routine evaluation diagram of the patients who applied to our outpatient clinic in terms of osteoporosis. The patients included in our study were divided into two groups according to their BMI as "pre-obese/normal" for those with a BMI < $30(\mathrm{n}=26)$, and "obese" for those with a BMI $\geq 30$ ( $\mathrm{n}=$ 69) (14).

\begin{tabular}{|l|l|}
\hline - Patient \\
\hline - Routine Blood Analysis \\
\hline - Bonoracolumbar Spine X-Rays \\
\hline - Evaluation of Data-FRAX Composition Density Measurement \\
\hline
\end{tabular}

Figure 1. Routine evaluation diagram of patients in terms of osteoporosis

SSPS $^{\circledast}$ version 21.0 statistical package program (SPSS Inc., Chicago, IL, USA) was used for statistical analysis. In the statistical analysis, after evaluating whether the data showed normal distribution or not, using the Kolmogorov Smirnov test, independent samples t-test was applied to the parameters showing normal distribution, while the Mann Whitney U test was used for the parameters that did not show normal distribution. $\mathrm{P}<0.05$ values were considered statistically significant.

\section{RESULTS}

It was determined that $25.3 \%$ of the type $2 \mathrm{DM}$ patients included in the study were male, $74.7 \%$ were female, and the general average age was $60.589( \pm 8.20)$. When the demographic characteristics are examined according to the BMI classification in Table 2, the average age of the patients was found to be $60.44( \pm 9.00)$ in the obese and $60.96( \pm 5.68)$ in the pre-obese/normal. In addition, according to the BMI grouping, the mean duration of disease diagnosis was $12.36( \pm 8.37)$ years in the obese group, while it was $14.80( \pm 8.47)$ years in the pre-obese/ normal group, and the p-value between the duration of diagnosis and the BMI groups was found to be 0.215 . There was no significant difference between the two groups in terms of smoking.

\begin{tabular}{|lccc|}
\hline Table 2. Demographic characteristics according to BMI classification \\
\hline $\begin{array}{l}\text { BMI }<\mathbf{3 0} \\
\text { (Pre-obese/Normal) }\end{array}$ & $\begin{array}{c}\text { BMI } \geq \mathbf{3 0} \\
\text { (Obese) }\end{array}$ & $\begin{array}{c}\text { P } \\
\text { value }\end{array}$ \\
\hline $\begin{array}{l}\text { Age (year) } \\
\text { Gender } \\
\text { (n: female/male) }\end{array}$ & $60.96( \pm 5.68)$ & $60.44( \pm 9.00)$ & .743 \\
DM time (year) & $16 / 10$ & $55 / 14$ & .087 \\
Smoking rate & $11.5 \%$ & $12.36( \pm 8.37)$ & .215 \\
& & $7.2 \%$ & .574 \\
\hline
\end{tabular}


FRAX and BMD values according to the BMI classification are shown in Table 3. When the groups were compared in terms of FRAX and BMD values, it was noted that the averages of these values were higher in the obese group. When FRAX and BMD values are examined according to BMI classification in Table 3, FRAX hip, L1-L4 total T score, femoral neck T score, femur total $\mathrm{T}$ score and femur total $\mathrm{g} / \mathrm{cm}^{2}$ values were found to be significantly higher in the obese group $(\mathrm{p}<0.05)$.

Table 3. FRAX and BMD values according to BMI classification

\begin{tabular}{|c|c|c|c|c|c|}
\hline & \multicolumn{2}{|c|}{$\begin{array}{c}\text { BMI }<30 \\
\text { (Pre-obese/Normal) }\end{array}$} & \multicolumn{2}{|c|}{$\begin{array}{c}\text { BMI } \geq 30 \\
\text { (Obese) }\end{array}$} & \multirow[b]{2}{*}{$\underset{\text { value }}{p}$} \\
\hline & Mean & $\begin{array}{c}\text { Std. } \\
\text { Deviation }\end{array}$ & Mean & $\begin{array}{c}\text { Std. } \\
\text { Deviation }\end{array}$ & \\
\hline FRAX major & 6.353 & 1.875 & 6.518 & 3.931 & .341 \\
\hline FRAX hip & 0.542 & 0.404 & 0.629 & 1.203 & $.018^{\star}$ \\
\hline $\begin{array}{l}\text { L1-L4 total } \\
\text { T score }\end{array}$ & -0.073 & 1.578 & 0.727 & 1.761 & $.047^{\star}$ \\
\hline $\begin{array}{l}\mathrm{L} 1-\mathrm{L} 4 \text { total } \\
\mathrm{g} / \mathrm{cm}^{2}\end{array}$ & 1.142 & 0.202 & 1.238 & 0.222 & .052 \\
\hline $\begin{array}{l}\text { Femoral neck } \\
\text { T score }\end{array}$ & -0.719 & 0.753 & 0.215 & 1.919 & $.019^{*}$ \\
\hline $\begin{array}{l}\text { Femoral neck } \\
\mathrm{g} / \mathrm{cm}^{2}\end{array}$ & 0.917 & 0.120 & 1.018 & 0.237 & .060 \\
\hline $\begin{array}{l}\text { Femur total } \\
\text { T score }\end{array}$ & -0.396 & 0.944 & 0.755 & 1.925 & $.001^{*}$ \\
\hline $\begin{array}{l}\text { Femur total } \\
\mathrm{g} / \mathrm{cm}^{2}\end{array}$ & 0.979 & 0.132 & 1.108 & 0.239 & $.006^{*}$ \\
\hline
\end{tabular}

In addition, while the history of low-energy fracture was $8.69 \%$ in the obese group, there was no fracture history in the pre-obese/normal group. While fractures were seen in the obese group with a rate of $17.39 \%$, in the pre-obese/ normal group, fractures were detected in $3.84 \%$ in the $\mathrm{X}$-ray scan. Accordingly, although the low-energy fracture history and the number of fractures detected in the $\mathrm{X}$-ray scan were higher in the obese group, no significant difference was observed between the two groups $(\mathrm{p}>0.05)$.

\section{DISCUSSION}

In this study, obese and pre-obese/normal patient groups diagnosed with type $2 \mathrm{DM}$ with similar lifestyles (smoking and alcohol consumption), average age and duration of diagnosis were examined. There was a significant difference between the groups in terms of BMD values (L1-L4 total T score, femoral neck T score, femur total T score, and femur total $\mathrm{g} / \mathrm{cm}^{2}$ ) and FRAX hip fracture. Obesity is a common finding in patients with type $2 \mathrm{DM}$. Obesity is thought to improve bone quality and mass by increasing the tension on the skeleton, thus protecting it from osteoporosis(15). However, in the study conducted by Nielson et al. (16) on 5918 obese and elderly men, it was found that obesity was not protective against fracture angle. Again, in the study of Tanaka et al. (17) 1614 on female patients in the postmenopausal period, obesity was associated with an increased incidence of vertebral fractures. Similarly, higher BMD values were found in the patient group with a BMI $\geq 30$ in our study. However, in this group, it was observed that the number of patients with a history of fracture, fracture on X-ray and the mean FRAX major and FRAX hip values were higher than the patient group with a BMI <30. Low-energy fracture history, family history of hip fractures, current smoking may be the reason for the high fracture risk according to the FRAX score despite the high BMD values in the obese group in our study.

Although DXA is accepted as the gold standard analysis in measuring BMD (18), it is known that type $2 \mathrm{DM}$ has effects on the bone that cannot be measured by the DXA device (15). Despite high BMD values, there is a high risk of fractures in patients with type $2 \mathrm{DM}$. Although fragility of bone increases in type 2 DM, FRAX underestimates the risk of bone fracture (19). Obesity, which is common in patients diagnosed with type $2 \mathrm{DM}$, can be shown as one of the reasons for these effects (20). Type $2 \mathrm{DM}$ and obesity have been found to cause deterioration in bone quality by affecting bone remodeling (20). The practical way to adjust the fracture risk in these patients is to reduce the standard deviation of 0.5 in the BMD T score (21).

Although type $2 \mathrm{DM}$ affects bone metabolism with many mechanisms, its results are controversial. A study conducted in Brazil showed that blood glucose control is not an independent risk factor for vertebral fracture(22). However, an in vivo study by Garcia et al. (23), it was found that high blood glucose levels decrease bone mineral quality by affecting the biomineralization in osteoblasts. Serum levels of osteocalcin, which has an important role in binding calcium and hydroxyapatite crystals to bone, were found to be low in patients with type $2 \mathrm{DM}$ (24).

Melton et al. (25), evaluated bone structure and strength with quantitative computed tomography in their study consisting of diabetic patients and nondiabetic control groups. In this study, it was shown that despite higher $\mathrm{BMD}$ values in patients with type $2 \mathrm{DM}$, this increase was entirely due to trabecular bone. In another crosssectional study, higher trabecular volume was found in patients with postmenopausal type $2 \mathrm{DM}$ compared to the control group, but cortical bone strength was found to be impaired (26). The mechanisms behind these changes in type $2 \mathrm{DM}$ are mainly related to obesity, diabetic complications, age, duration of diabetes, comorbidities and medications (27). In our study, although BMD values were higher in the obese patient group with a diagnosis of type $2 \mathrm{DM}$, the average FRAX and the number of patients with fractures were found to be higher than in the preobese/normal group. 


\section{CONCLUSION}

In our study, when the obese and pre-obese/normal groups diagnosed with type $2 \mathrm{DM}$ were evaluated in terms of BMD values (L1-L4 total T score, femoral neck $\mathrm{T}$ score, femur total $\mathrm{T}$ score and femur total $\mathrm{g} / \mathrm{cm}^{2}$ ), a significant difference was found between the groups. However, when the patient groups are examined, fracture risk in the obese patient group is higher than in the pre-obese/normal group. More studies are needed to understand the relationship between diabetes, obesity, and fracture.

\section{ETHICAL DECLARATIONS}

Ethics Committee Approval: The study was carried out with the permission of Amasya University Noninterventional Clinical Research Ethics Committee (Date: 03.09.2020, Decision No: 9/104).

Informed Consent: Because the study was designed retrospectively, no written informed consent form was obtained from patients.

Referee Evaluation Process: Externally peer-reviewed.

Conflict of Interest Statement: The authors have no conflicts of interest to declare.

Financial Disclosure: The authors declared that this study had received no financial support.

Author Contributions: All of the authors declare that they have all participated in the design, execution, and analysis of the paper and approved the final version.

\section{REFERENCES}

1. Kurra S, Siris E. Diabetes and bone health: the relationship between diabetes and osteoporosis-associated fractures. Diabetes/ Metabolism Research and Reviews 2011; 27: 430-5.

2. De Waard EA, van Geel TA, Savelberg HH, Koster A, Geusens PP, Van Den Bergh JP. Increased fracture risk in patients with type 2 diabetes mellitus: an overview of the underlying mechanisms and the usefulness of imaging modalities and fracture risk assessment tools. Maturitas 2014; 79: 265-74.

3. Association AD. 2. Classification and diagnosis of diabetes. Diabetes Care 2017; 40: S11-S24.

4. Schwartz A. Diabetes mellitus: does it affect bone? Calcified Tissue International 2003; 73: 515-9.

5. Inzerillo AM, Epstein S. Osteoporosis and diabetes mellitus. Rev Endocr Metab Disord 2004; 5: 261-8.

6. Vestergaard P. Discrepancies in bone mineral density and fracture risk in patients with type 1 and type 2 diabetes-a meta-analysis. Osteoporos Int 2007; 18: 427-44.

7. Walsh JS; Vilaca T. Obesity, type 2 diabetes and bone in adults. Calcif Tissue Int 2017; 100: 528-35.

8. Felson DT, Zhang Y, Hannan MT, Anderson JJ. Effects of weight and body mass index on bone mineral density in men and women: the Framingham study. J Bone Miner Res 1993; 8: 567-73.

9. Schwartz AV, Sellmeyer DE, Ensrud KE, et al. Older women with diabetes have an increased risk of fracture: a prospective study. J Clin Endocrinol Metabol 2001; 86: 32-8.
10. Forsen L, Meyer H, Midthjell K, Edna TH. Diabetes mellitus and the incidence of hip fracture: results from the Nord-Trøndelag Health Survey. Diabetologia 1999; 42: 920-5.

11.Janghorbani M, Van Dam RM, Willett WC, Hu FB. Systematic review of type 1 and type 2 diabetes mellitus and risk of fracture. Am J Epidemiol 2007; 166: 495-505.

12.Kanis JA, McCloskey EV, Johansson H, Cooper C, Rizzoli R, Reginster JY. European guidance for the diagnosis and management of osteoporosis in postmenopausal women. Osteoporosis Int 2013; 24: 23-57.

13. Unni S, Yao Y, Milne N, Gunning K, Curtis J, LaFleur J. An evaluation of clinical risk factors for estimating fracture risk in postmenopausal osteoporosis using an electronic medical record database. Osteoporosis Int 2015; 26: 581-7.

14. Organization WH. The Asia-Pacific perspective: redefining obesity and its treatment. 2000.

15. Sealand R, Razavi C, Adler RA. Diabetes mellitus and osteoporosis. Curr Diabetes Rep 2013; 13: 411-8.

16. Nielson CM, Marshall LM, Adams AL, et al. BMI and fracture risk in older men: the osteoporotic fractures in men study (MrOS). J Bone Miner Res 2011; 26: 496-502.

17. Tanaka S, Kuroda T, Saito M, Shiraki M. Overweight/obesity and underweight are both risk factors for osteoporotic fractures at different sites in Japanese postmenopausal women. Osteoporosis Int 2013; 24: 69-76.

18. Eryavuz Sarıdoğan M. Osteoporozun tanımı ve sinıflandırması. Modern Tip Seminerleri 19: Osteoporoz 2001: 1-5.

19. Fassio A, Idolazzi L, Rossini M, et al. The obesity paradox and osteoporosis. Eat Weight Disord 2018; 23: 293-302.

20. de Paula FJ, Rosen CJ. Obesity, diabetes mellitus and last but not least, osteoporosis. Arq Bras Endocrinol Metabol 2010; 54: 150-7.

21.Pritchard JM, Giangregorio LM, Atkinson SA, et al. Changes in trabecular bone microarchitecture in postmenopausal women with and without type 2 diabetes: a two year longitudinal study. BMC Musculoskelet Disord 2013; 14: 114.

22. Viégas M, Costa C, Lopes A, Griz L, Medeiro MA, Bandeira F. Prevalence of osteoporosis and vertebral fractures in postmenopausal women with type 2 diabetes mellitus and their relationship with duration of the disease and chronic complications. J Diabetes Complications 2011; 25: 216-21.

23. García-Hernández A, Arzate H, Gil-Chavarria I, Rojo R, MorenoFierros L. High glucose concentrations alter the biomineralization process in human osteoblastic cells. Bone 2012; 50: 276-88.

24. Kanazawa I, Yamaguchi T, Yamamoto M, et al. Serum osteocalcin level is associated with glucose metabolism and atherosclerosis parameters in type 2 diabetes mellitus. J Clin Endocrinol Metabol 2009; 94: 45-9.

25. Melton III LJ, Riggs BL, Leibson CL, et al. A bone structural basis for fracture risk in diabetes. J Clin Endocrinol Metabol 2008; 93: 4804-9.

26. Burghardt AJ, Issever AS, Schwartz AV, et al. High-resolution peripheral quantitative computed tomographic imaging of cortical and trabecular bone microarchitecture in patients with type 2 diabetes mellitus. J Clin Endocrinol Metabol 2010; 95:5045-55.

27.Lecka-Czernik B. Bone loss in diabetes: use of antidiabetic thiazolidinediones and secondary osteoporosis. Curr Osteoporos Rep 2010; 8: 178-84. 